\title{
Hierarchical porous carbon nanofibers via electrospinning
}

\author{
Aikifa Raza ${ }^{1}$, Jiaqi Wang ${ }^{1}$, Shan Yang ${ }^{2}$, Yang $\mathrm{Si}^{1}$ and Bin Ding ${ }^{1,3, *}$ \\ ${ }^{1}$ State Key Laboratory for Modification of Chemical Fibers and Polymer Materials, College of Materials Science and Engineering, \\ Donghua University, Shanghai 201620, China \\ ${ }^{2}$ College of Textiles, Donghua University, Shanghai 201620, China \\ ${ }^{3}$ Nanomaterials Research Center, Modern Textile Institute, Donghua University, Shanghai 200051, China
}

\section{Article Info}

Received 4 November 2013

Accepted 2 January 2014

*Corresponding Author

E-mail: binding@dhu.edu.cn

\section{Open Access}

DOI: http://dx.doi.org/

10.5714/CL.2014.15.1.001

This is an Open Access article distributed under the terms of the Creative Commons Attribution Non-Commercial License (http://creativecommons.org/licenses/ by-nc/3.0/) which permits unrestricted non-commercial use, distribution, and reproduction in any medium, provided the original work is properly cited.

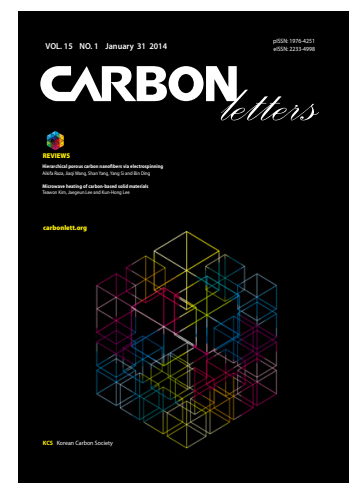

http://carbonlett.org

pISSN: $1976-4251$

elSSN: 2233-4998

Copyright $\odot$ Korean Carbon Society

\begin{abstract}
Carbon nanofibers (CNFs) with diameters in the submicron and nanometer range exhibit high specific surface area, hierarchically porous structure, flexibility, and super strength which allow them to be used in the electrode materials of energy storage devices, and as hybrid-type filler in carbon fiber reinforced plastics and bone tissue scaffold. Unlike catalytic synthesis and other methods, electrospinning of various polymeric precursors followed by stabilization and carbonization has become a straightforward and convenient way to fabricate continuous CNFs. This paper is a comprehensive and brief review on the latest advances made in the development of electrospun CNFs with major focus on the promising applications accomplished by appropriately regulating the microstructural, mechanical, and electrical properties of as-spun CNFs. Additionally, the article describes the various strategies to make a variety of carbon CNFs for energy conversion and storage, catalysis, sensor, adsorption/separation, and biomedical applications. It is envisioned that electrospun CNFs will be the key materials of green science and technology through close collaborations with carbon fibers and carbon nanotubes.
\end{abstract}

Key words: hierarchically porous carbon nanofibers, activated carbon nanofibers, electrospinning, polymer precursors

\section{Introduction}

Carbon fibers are high aspect ratio graphitic fibers, and possess great technical and industrial importance due to their wide-ranging properties, like very high strength to weight ratio, superior electrical and thermal conductivity, and excellent chemical resistance [1]. Besides other applications, carbon fibers have been predominantly used in high-performance fiberreinforced composites, which are extremely desirable in automotive, aerospace, and sport industries. These fibers have gained a lot of attention since Iijima reported his results on the closely-related carbon nanotubes (CNTs), thus creating a revolution in the arena of nanotechnology in 1991 [2]. Based on valuable developments in the nano-era, wide potential applications for carbon fibers were projected and huge efforts were focused on their synthesis, in order to improve their properties, which caused an exponential increase in the number of related research articles published in the last two decades.

Generally two approaches have been adopted to fabricate carbon nanofibers (CNFs): vapor growth and electrospinning methods (Figs. 1a and a') [3]. In the thermal growth method, the carbon fibers are fabricated through catalytic decomposition of certain hydrocarbons in the presence of catalysts (metal particles), but this method entails great difficulties for the mass-production of CNFs. Besides this, other conventional preparation methods for CNFs are also recognized to be very complicated and overpriced, including the spraying method, substrate method, and plasmaenhanced chemical vapor deposition method [4]. Therefore, a simple and low-cost electrospinning method, first patented by Cooley [5] in 1902, has gained a lot of attention during the last decade as the optimum method to produce continuous CNFs. 


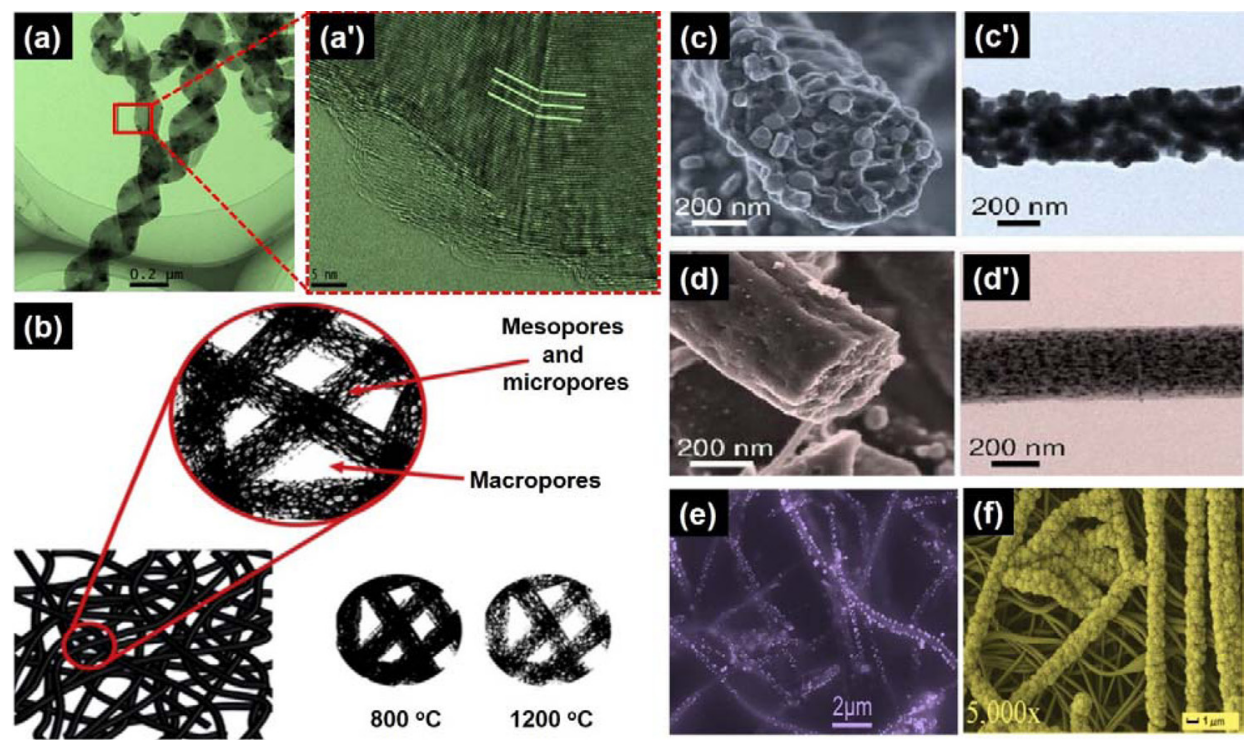

Fig. 1. Transmission electron microscope (TEM) image of (a) carbon nanofibers (CNFs) with twisting nanoribbon and (a') high-resolution TEM (HRTEM) image of twisting nanoribbon. (b) Scheme showing the hierarchical structure of CNFs. (c) Scanning electron microscope (SEM) and (c') TEM image of SnCo/ polyvinylpyrrolidone-CNFs. (d) SEM and (d') TEM image of SnCo/polyacrylonitrile-CNFs. SEM images (e) of the Pd/CNF-carbon paste electrode surface and (f) growth of hydroxyapatite on P-CNF. (a-a') Reprinted with permission from [3]. Copyright $\odot$ 2013, Authors. (b) Reprinted with permission from [54]. Copyright @ 2013, Elsevier. (c-d') Reprinted with permission from [31]. Copyright @ 2013, American Chemical Society. (e) Reprinted with permission from [55]. Copyright $\odot$ 2008, Elsevier. (f) Reprinted with permission from [56]. Copyright $\odot$ 2013, Elsevier.

\section{Electrospinning: a Useful Tool to Fabricate CNFs}

Recently, electrospinning has emerged as a powerful and highly versatile technique which allows micro- and nano-scale fibers to be fabricated from process polymeric solutions or melts using an electrically forced fluid jet [6]. Electrospinning shares the characteristics of both electrospraying and conventional solution dry spinning of fibers, and that makes the process particularly suited to the production of fibers using large and complex molecules on a multi-scale [7-10]. The right combination of electrospinning of organic polymers and subsequent thermal treatment in an inert atmosphere could lead to the mass production of CNFs. The fabrication of electrospun CNFs generally includes stabilization, carbonization, and sometimes graphitization, which is similar to the conventional processes for fabricating micrometre-sized carbon fibers. Depending upon the application, further physical and/or chemical activations can be used on the as-carbonized nanofibers to fabricate activated CNFs (ACNFs), which are considered to be outstanding highabsorption materials due to their excellent thermal and chemical stabilities, rapid adsorption rate, high adsorption capacity, and hydrophobicity.

Because of their peculiar structure, electrospun-based CNFs possess exceptional properties, such as nano-sized diameter, very high surface area, and thin web morphology, which make them ultra-suitable for the fabrication of high-performance nanocomposites, tissue scaffolds, sensing and energy storage devices [11]. In this review, we focus on electrospun CNFs prepared via electrospinning methods and subsequent carbonization, with a brief discussion of their structure and properties in relation to their applications. Due to the increase in research activities related to CNFs, herein we aim to present a comprehensive review on the development of electrospun CNFs fabricated using various polymeric precursors as well as their practical applications, and so reveal a complete picture of the research work in this field in the last few years.

\section{Precursors of CNFs}

Polymeric materials with a carbon back-bone can be used as the precursor of carbon fibers, but usually CNFs are produced from the polymeric precursors: polyacrylonitrile (PAN), cellulose, and pitch. Other precursors, such as poly(amic acid) (PAA), polyimide (PI), polybenzimidazole (PBI), poly(p-xylenetetrahydrothiophenium chloride) (PXTC), and poly(vinyl alcohol) (PVA), have also been reported. The microstructural characteristics of electrospun CNFs are extremely dependent on the physical and chemical natures of the precursor nanofibers. Therefore, controlling electrospinning conditions, like solution properties (temperature, concentration, solvent type, surface tension, and conductivity), processing parameters (applied voltage, spinneret diameter, solution flow rate, and tip to collector distance) as well as ambient conditions (relative humidity and temperature), can result in CNFs with relatively better or deteriorated performance [12].

\subsection{PAN based CNFs}

The most common polymer for the preparation of CNFs is PAN, mainly due to its high melting point and carbon yield along with the ease of attaining thermally stabilized products. In 
addition, the surface of PAN-based CNFs can easily be modified using a coating or activation process [13]. Furthermore, PAN can be mixed with other polymers or be embedded with nanoscale components (nanoparticles, nanotubes, nanowires, or catalysts) to obtain multiphase precursors and subsequently to make composite CNFs. Different types of PAN-based CNFs are summarized in the following.

\subsubsection{Pure PAN based CNFs}

During the last decade, detailed researches have investigated fabricating PAN based CNFs by electrospinning [14]. Similar to the production of carbon micro fibers, CNFs have been successfully prepared by electrospinning the PAN/dimethylformamide (DMF) polymer solution followed by a two-step process: stabilization and carbonization [15]. Various stabilization and carbonization conditions have been described, in which stabilization was carried out in air at temperatures between $200-300^{\circ} \mathrm{C}$ while carbonization was further performed in an inert atmosphere up to $2800^{\circ} \mathrm{C}$ [16]. Progressive and multi-stage heating methods were used to reduce mass loss and dimension shrinkage. The gradual stabilization and carbonization procedure of $5^{\circ} \mathrm{C} / \mathrm{min}$ from $30-230^{\circ} \mathrm{C}, 1^{\circ} \mathrm{C} / \mathrm{min}$ from $230-270^{\circ} \mathrm{C}$, and then $5^{\circ} \mathrm{C} / \mathrm{min}$ from $270-800^{\circ} \mathrm{C}$ led to very little change in fiber packing, much less planar dimensional shrinkage, with a significant increase of carbon yield as compared to the previously reported procedure [17].

Wang et al. [18,19] and Kim et al. [21,22] deeply investigated the effect of pyrolysis temperature using Raman spectroscopy, and reported that the positions and widths of the $\mathrm{D}$ and $\mathrm{G}$ peaks for electrospun PAN-based CNFs are insensitive to the pyrolysis temperature, while refractive index (RI) and crystallite width (La) was shown to have a steady decrease, and increase, with temperature, respectively. The value of $\mathrm{La}$ increased from 1.5 $\left(600^{\circ} \mathrm{C}\right)$ to $2.64 \mathrm{~nm}\left(1200^{\circ} \mathrm{C}\right)$ and from $1.6\left(700^{\circ} \mathrm{C}\right)$ to $3.17 \mathrm{~nm}$ $\left(1000^{\circ} \mathrm{C}\right)$. The large negative magneto resistance along with low La values present in the $\mathrm{CNFs}\left(1000^{\circ} \mathrm{C}\right)$, when positioned in a magnetic field at low-temperature, between 1.9-300 K, could establish the formation of a turbostratic structure [19]. A very high degree of carbonization is evidenced when CNFs are treated at a relatively high temperature $\left(2800^{\circ} \mathrm{C}\right)$, as indicated by a very sharp G peak and weak D peak in the Raman spectra. Zussman et al. [20] also investigated the microstructural properties of electrospun PAN-based CNFs that had undergone heat treatment. CNFs heated from 700 to $1000^{\circ} \mathrm{C}$ had a low degree of carbonization with an average crystallite size (Lc) of 1.284 $\mathrm{nm}$ [20]. However, it was found that the RI of CNFs was 0.925 \pm 0.04 and was less than 0.5 after heat treatment at $2000^{\circ} \mathrm{C}$, revealing a higher degree of carbonization and a more ordered structure [21].

The fabrication of CNF webs, consisting of CNFs obtained through the activation of electrospun PAN-based CNFs having highly hierarchically porous structures, can lead to a significant expansion of applications of CNFs, such as in electrode materials, high-temperature filtration and the emoval of toxic gases. Steam is widely used as an activating agent for fabricating ACNFs because of its low cost and environmentally friendly characteristics (Fig. 1b). Kim and Yang [22] reported that the specific surface area of steam-ACNFs decreased with increasing activation temperature (from $700-850^{\circ} \mathrm{C}$ ) due to the unification of micropores at elevated temperatures.

\subsubsection{Composite PAN based CNFs}

In order to create some functional properties in PAN-based $\mathrm{CNFs}$, a variety of nanomaterials have been integrated into precursor solutions to fabricate composite CNFs by co-electrospinning and subsequent thermal treatment. High orientation of the PAN chains were induced by creating significant interactions using a thermal treatment between PAN and CNTs. The relative orientation coefficient adjacent to multi-walled CNTs (MWCNTs) in the core region of CNFs was 0.79 , higher than that without CNTs, 0.44, and the relative orientation coefficient and crystallite size increased with an increase of MWCNTs concentration. At the same time, the diameter of the as-spun nanofibers could be decreased with an increase of CNTs content due to the resulting higher electrical conductivity [23]. Later, continuous single-walled CNTs (SWCNTs) were incorporated into PANbased CNF yarns using a drum as the collector. A non-graphitized structure including graphite layers and disordered carbon was formed after graphitization at $1100^{\circ} \mathrm{C}$. The modulus of the stabilized SWCNT/PAN composite nanofibers was increased from 60 to $150 \mathrm{GPa}$ by increasing the SWCNT content from 0-4 $w t \%$. Although SWCNTs might protrude out of the composite CNFs due to the shrinkage of the fibers during thermal treatment, forming a rough surface, well-distributed and oriented CNTs were achieved in almost every section investigated, which is favorable for enhancing mechanical, electrical and thermal properties [24]. Positron annihilation spectroscopy is recognized as a versatile method for checking the evolution of vacancy-type flaws and their clusters in solid materials. Ra et al. [13] first employed the method to study electrospun CNFs embedded with MWCNTs composite and found that discrete positron trapping sites in the form of vacancy-type defects formed at the interfaces among the MWCNTs and PAN matrix.

Besides MWCNTs, other inorganic species (e.g. Ag, $\mathrm{TiO}_{2}$ and $\mathrm{Mn}$ ) have also been added into the PAN precursor solution to prepare functional composite CNFs. PAN/Ag nanofibers were obtained, and the diameter of the CNFs varied with the Ag content from $0-5 \mathrm{wt} \%$; the smallest CNFs were obtained at $1 \mathrm{wt} \%$, which is in disagreement with the rule that the diameter usually increases with increasing conductivity of the solution [13]. Kim and Lim [25] investigated the physicochemical and photocatalytic activities of oxidized $\mathrm{TiO}_{2}$-embedded PAN-based CNFs $\left(\mathrm{Ox}-\mathrm{TiO}_{2} / \mathrm{CNF}\right)$. Brunauer-Emmett-Teller (BET) specific surface area of the $\mathrm{Ox}-\mathrm{TiO}_{2} / \mathrm{CNF}$ exhibited a large increase, from $42-223 \mathrm{~m}^{2} \mathrm{~g}^{-1}$ after post-oxidization, due to the loss of carbon in gaseous form [25]. Oh et al. [26] studied the pore characteristics of Mn-embedded PAN-based ACNFs. By controlling the dispersion of $\mathrm{Mn}$ in the resulting composite ACNFs, large specific surface area and micropore volume could be expected due to the physical migration of Mn and its catalytic activation [26]. Recently, hierarchical porous CNFs were incorporated with $\mathrm{Fe}_{3} \mathrm{O}_{4}$ nanocrystals using electrospun PAN/polybenzoxazine (PBZ) nanofibers as the composite carbon precursor. By the combination of precursor design and activation process, an extremely high surface area of $1623 \mathrm{~m}^{2} \mathrm{~g}^{-1}$ and a pore volume of 1.635 $\mathrm{cm}^{3} \mathrm{~g}^{-1}$ were obtained. Quantitative pore size distribution and fractal analysis were used to investigate the hierarchical porous structure using $\mathrm{N}_{2}$ adsorption methods and synchrotron radiation small-angle X-ray scattering measurements [27,28].

The surface modification techniques applied to electrospun 
CNFs can combine the advantages of the coating materials and the large specific surface area of the nanofibrous substrate to provide composite CNFs with more features. Polypyrrole (PPy) was coated on as-obtained PAN-based ACNFs, which were embedded with $5.7 \mathrm{wt} \%$ MWCNTs [29]. A three-dimensional (3D) network of PPy particles was well organized on the surface of the ACNFs/MWCNTs. Specific surface area, mesopore volume, total pore volume, average pore size, and electrical conductivity were all increased after the incorporation of the MWCNTs in the ACNFs. Unlike previous studies which used carbonization prior to surface coating, Shao et al. [30] fabricated zinc oxide ( $\mathrm{ZnO})$-coated PAN-based CNFs using sol-gel coating followed by thermal treatment. Separated $\mathrm{ZnO}$ clusters with a diameter of $100 \mathrm{~nm}$ and perfect crystalline structure were formed after the carbonization. This special surface might be favorable for some interesting applications. However, due to the low carbonization temperature $\left(450^{\circ} \mathrm{C}\right)$, the CNFs still exhibited an amorphous structure [30]. Recently, Shin et al. [31] synthesized two distinct 1-D CNFs encapsulating irregularly isolated $\mathrm{SnCo}$ nanoparticles via electrospinning of polyvinylpyrrolidone (PVP), and PAN polymers containing Sn-Co acetate precursors with subsequent calcination in reducing atmosphere. CNFs fabricated with PVP undergo structural degradation of the polymer during the carbonization processes, and have exhibited irregular segregation of heterogeneous alloy particles with a size distribution of 30-100 nm, as shown in Figs. 1c and d [31].

\subsection{Pitch based CNFs}

Pitch, another precursor used to fabricate CNFs, is generally obtained from petroleum asphalt, coal tar, and poly(vinyl chloride), and has a higher carbon yield and a lower cost compared to PAN [32,33]. However, impurities in the pitch must be fully removed to obtain high-performance carbon fibers, leading to a great increase in cost. Park et al. [34] reported that a DMF/ tetrahydrofuran (THF) solvent mixture containing $40 \mathrm{wt} \%$ pitch could be electrospun and the diameter of the as-spun pitch fibers was in the micrometer range; it was difficult to make them thinner due to the low boiling point $\left(65-67^{\circ} \mathrm{C}\right)$ of the solvent (THF). For the same pitch precursor, the performance of electrospun activated carbon microfibers was compared with that of melt-spun activated carbon microfibers and the results showed that the electrospun carbon microfibers had a higher activation reaction rate compared to melt-spun fibers, because of the finer diameter and less ordered microstructure [35]. BET specific surface area of the electrospun activated carbon microfibers decreased with activation temperature from $700-900^{\circ} \mathrm{C}$, which is opposite to the increased trend obtained by Oh et al. [26] for PAN-based ACNFs treated from $800-1000^{\circ} \mathrm{C}$. This was possibly due to the precursor type and the large diameter difference [26].

\subsection{PVA based CNFs}

PVA, another thermoplastic polymer, is a water-soluble polyhydroxy polymer and has been used as a carbon precursor in fundamental researches, even though it easily decomposes at a high temperature and gives a low carbon yield. Zhu et al. [36] fabricated $\mathrm{Fe}_{3} \mathrm{O}_{4}$-filled PVA-based composite CNFs through carbonization at a relatively low carbonization temperature of $600^{\circ} \mathrm{C}$ considering transition metals as a catalyst. The resultant carbonized CNFs have shown good conductivity, magnetic, and hydrophobic properties. Theoretically, the increased electrical conductivity of the spinning solution with increasing $\mathrm{FeAc}_{2}$ content could be predicted to reduce the diameter of the electrospun hybrid nanofibers. However, the diameter of the electrospun $\mathrm{FeAc}_{2}$ containing nanofibers was increased with an increase of $\mathrm{FeAc}_{2}$ content [36]

\subsection{PI based CNFs}

Unlike these thermoplastic precursors, electrospun thermosetting nanofibers like PI can directly undergo carbonization for the fabrication of CNFs without the need of the expensive stabilization process, and have thus gained increasing attention in recent years [37-39]. Kim et al. [40] reported the formation of yellow electrospun webs of PAA at voltages between $13-15 \mathrm{kV}$, which were then imidized with $81 \%$ yield. The imidized webs were then carbonized at $700-1000^{\circ} \mathrm{C}$ under a nitrogen atmosphere with yields greater than or equal to $53 \%$. The carbonized webs were activated under steam in the temperature range of $650-850^{\circ} \mathrm{C}$ resulting in a specific surface area of $940-2100 \mathrm{~m}^{2} / \mathrm{g}$ [40]. Xuyen et al. [37] described that pressure during the carbonization process could play an important role in the electrical conductivity of PI-based CNF mat [37]. Chung et al. [41] embedded iron(III) acetylacetonate (AAI) into PI-based CNFs and investigated the effect of AAI on the degree of carbonization. It was found that AAI acted as an effective promoting agent for the carbonization as indicated by a sharper diffraction peak, lower RI and larger crystallite size [41].

\subsection{PBI based CNFs}

Aside from PI as a precursor, a series of investigations of PBI-based CNFs and ACNFs were conducted by Kim and coworkers [42]. The electrical conductivity of PBI-based CNFs showed a steady increase from $5.74 \times 10^{-3}$ to $35 \mathrm{~S} \mathrm{~cm}^{-1}$ as the carbonization temperature was increased from $700-3000^{\circ} \mathrm{C}$. The major reason might be the rigid-chain structure possessed by PBI. Even though the PBI-based CNFs treated at $3000^{\circ} \mathrm{C}$ are still non-graphitizable carbons, as proved by X-ray diffraction, Raman spectra indicated a very high degree of graphitization. BET surface area kept on increasing with increasing temperature to $800^{\circ} \mathrm{C}$ and then decreased if electrospun PBI was further heated to $850^{\circ} \mathrm{C}$. This trend is different from PAN-based CNFs, which showed a steady decrease in the same temperature range.

\subsection{PXTC based CNFs}

Aligned nanofiber yarn several centimeters long was obtained by electrospinning another thermosetting polymer precursor (PXTC) [43]. The formation of the yarn might result from the ionic conduction of PXTC. The presence of D and G peaks in the Raman spectra signaled a successful change from electrospun PXTC yarn to CNFs in the temperature range from 600 $1000^{\circ} \mathrm{C}$; yarn carbonized at $500^{\circ} \mathrm{C}$ did not show these two peaks in the Raman spectra. The mole fraction of graphite for the carbonized nanofibers was determined to be 0.21-0.24. 

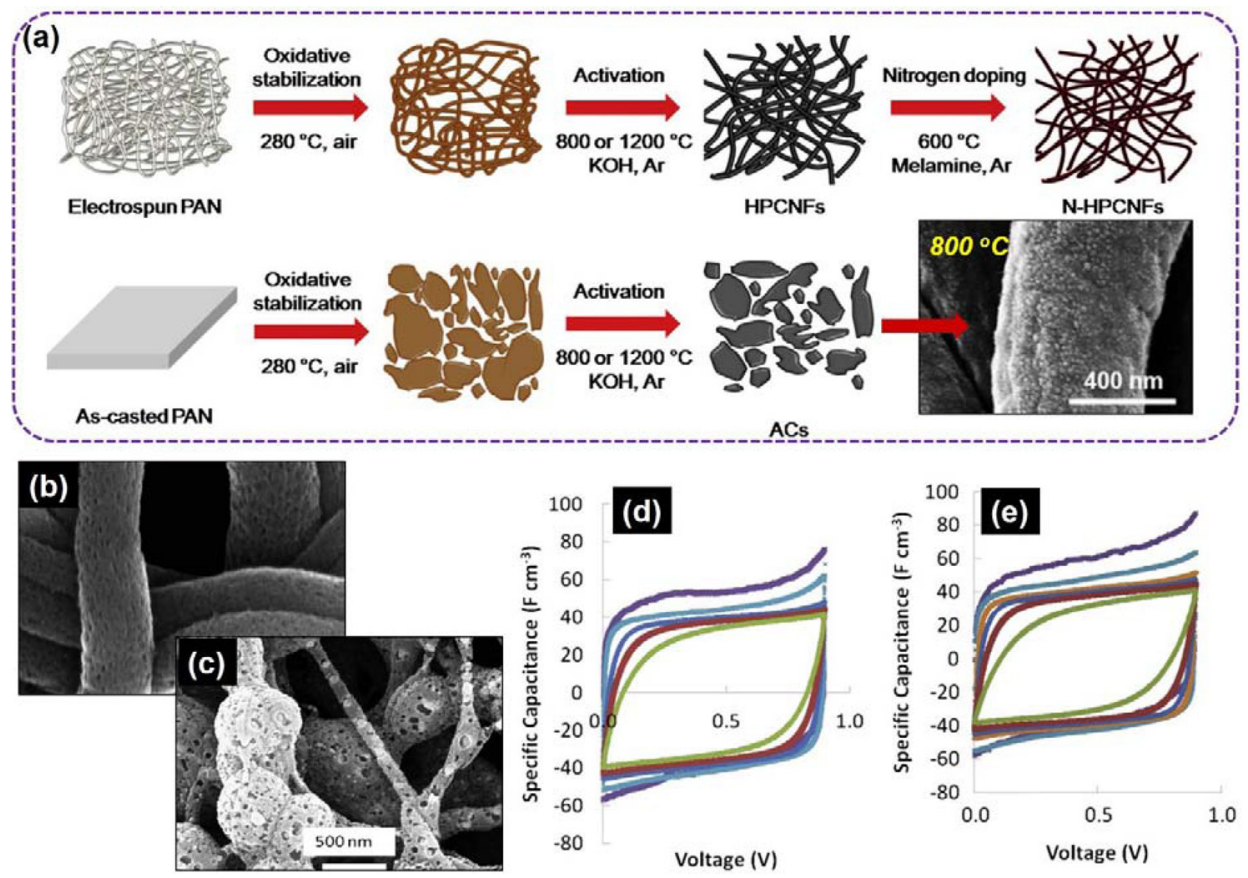

Fig. 2. (a) Scheme for the processing of activated carbons (ACs), hierarchically porous carbon nanofibers (CNFs), and nitrogen-doped hierarchically porous CNFs. Scanning electron microscope micrographs of porous CNFs formed by carbonizing nanofibers at different Nafion:polyacrylonitrile (PAN) blend compositions: (b) 80:20 electrospun at 25\% total solid concentration, (c) 80:20 electrospun at 20\% total solid concentration. Cyclic voltammetry of (d) carbonized 60:40 Nafion:PAN and (e) carbonized 80:20 Nafion:PAN. (a) Reprinted with permission from [54]. Copyright $\odot$ 2013, Elsevier. (b-e) Reprinted with permission from [57]. Copyright $\odot$ 2013, Elsevier.

\section{Applications of Electrospun CNFs}

Advanced energy conversion and storage systems, like supercapacitors, rechargeable lithium-ion batteries (LIBs), and fuel cells, are in urgent demand to fulfil newly emerging applications such as portable electronics, electric vehicles, and industrial power management. The performance of these devices strongly depends on the properties of the electrode materials used. CNFs have advantages similar to a $1 \mathrm{D}$ carbon nanostructure with the additional benefits of being inexpensive, continuous, and relatively easy to use in applications.

\subsection{Electrode materials for electrochemical capacitors}

Porous carbon materials are essential for electrodes materials for electrochemical capacitors; in commercially available capacitors, activated carbons are commonly used. Iijima and Ichihashi [44] first used webs of PAN-based CNFs as electrodes of electric double-layer capacitors, using $30 \mathrm{wt} \%$ potassium hydroxide $(\mathrm{KOH})$ aqueous solution. The $700^{\circ} \mathrm{C}$ activated webs gave a very high capacitance of $173 \mathrm{~F} \mathrm{~g}^{-1}$ at a low discharge current density, as low as $10 \mathrm{~mA} \mathrm{~g}^{-1}$, but at the higher current density of $1000 \mathrm{~mA}$ $\mathrm{g}^{-1}$ the $800^{\circ} \mathrm{C}$ activated webs gave a high capacitance of $120 \mathrm{~F}$ $\mathrm{g}^{-1}$. They reported that the former had a surface area of $1230 \mathrm{~m}^{2}$ $\mathrm{g}^{-1}$ containing micropores, but the latter had a surface area of 850 $\mathrm{m}^{2} \mathrm{~g}^{-1}$ consisting of mesopores. Similar results were obtained in later works $[45,46]$. PAN-based CNFs prepared by mixing PAN with $15 \mathrm{wt} \%$ cellulose acetate gave surface areas of $919 \mathrm{~m}^{2} \mathrm{~g}^{-1}$ and $241 \mathrm{~m}^{2} \mathrm{~g}^{-1}$, and therefore showed a capacitance of $245 \mathrm{~F} \mathrm{~g}^{-1}$ with a current density of $1 \mathrm{~mA} \mathrm{~cm}^{-2}$ [47].

MWCNTs dispersed in CNFs have given improved electric double-layer capacitor performance in aqueous electrolytes. The addition of $3 \mathrm{wt} \%$ MWCNTs in PAN precursor increased the surface area to $1170 \mathrm{~m}^{2} \mathrm{~g}^{-1}$ and electrical conductivity to 0.98 $\mathrm{S} \mathrm{cm}^{-1}$, and consequently increased electrical double-layer capacitor capacitance to $180 \mathrm{~F} \mathrm{~g}^{-1}$ in $6 \mathrm{M} \mathrm{KOH} \mathrm{[29].} \mathrm{A} \mathrm{coating} \mathrm{of}$ polypyrole (PPy) on these MWCNT-embedded CNFs led to a further rise in capacitance, to $333 \mathrm{~F} \mathrm{~g}^{-1}$. For MWCNT-embedded CNFs, electrical conductivity and capacitance increased to 5.32 $\mathrm{S} \mathrm{cm}^{-1}$ and $310 \mathrm{~F} \mathrm{~g}^{-1}$, respectively, from $0.86 \mathrm{~S} \mathrm{~cm}^{-1}$ and $170 \mathrm{~F}$ $\mathrm{g}^{-1}$ for the nanofibers without MWCNTs [48]. Composite CNFs containing $\mathrm{V}_{2} \mathrm{O}_{5}$ prepared via electrospinning revealed that the content of $\mathrm{V}_{2} \mathrm{O}_{5}$ was the major factor responsible for the morphology and pore structures [49]. An electrode made of these $\mathrm{C} / \mathrm{V}_{2} \mathrm{O}_{5}$ composite nanofibers led to the highest specific capacitance of $150 \mathrm{~F} \mathrm{~g} \mathrm{~g}^{-1}$ and energy density of $18.8 \mathrm{~W} \mathrm{~h} \mathrm{~kg}^{-1}$ over a power density range of 400-20 $000 \mathrm{~W} \mathrm{~kg}^{-1}$. In another report, boric acid $\left(\mathrm{H}_{3} \mathrm{BO}_{3}\right)$ and urea were used to introduce boron and nitrogen functional groups in CNFs and to increase total surface area [50]. The electrode with these characteristics demonstrated better supercapacitor performances, with specific capacitance of $180 \mathrm{~F} \mathrm{~g}^{-1}$ and energy density of $17.2-23.5 \mathrm{~W} \mathrm{~h} \mathrm{~kg}^{-1}$ in the power density range of 400-10 $000 \mathrm{~W} \mathrm{~kg}^{-1}$.

Continuous graphene-embedded CNFs were fabricated by electrospinning PAN-DMF solution with oxidized graphene nanosheets followed by carbonization at $800^{\circ} \mathrm{C}$. The electrochemical measurements revealed the maximum specific capacitance of $263.7 \mathrm{~F} \mathrm{~g}^{-1}$ in $6 \mathrm{M} \mathrm{KOH}$ aqueous electrolyte 

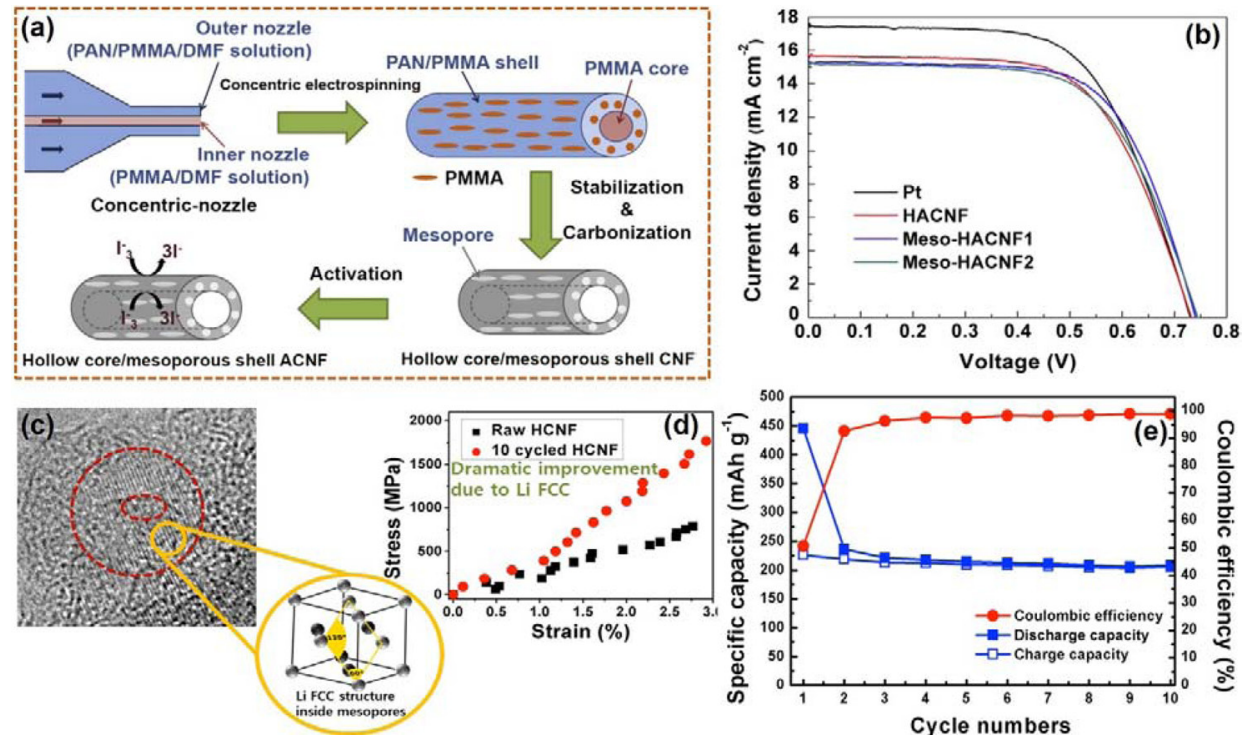

Fig. 3. (a) The fabricating process and $\mathrm{I}^{-3}$ reduction of activated carbon nanofibers (ACNFs) with hollow core/mesoporous shell structure. (b) I-V curves of hollow ACNF (HACNF), Meso-HACNF1, Meso-HACNF2, and Pt counter electrode. (c) High-resolution transmission electron microscope images of donutshaped lithium face centered cubic (FCC) metal crystallites and (d) stress-strain curves of hollow CNF (HCNF). (e) Cycling performances of freestanding HCNF anodes. ( $a$ and b) Reprinted with permission from [59]. Copyright $\odot$ 2013, Elsevier. (c-e) Reprinted with permission from [70]. Copyright $\odot ~ 2013$, American Chemical Society.

[51]. Similar graphene-integrated CNFs were prepared by using graphene in PAN/poly(methyl methacrylate) (PMMA) or PAN/TEOS [52]. Hierarchical pore structures with ultramicropores and mesopores were introduced and the supercapacitors made with these porous CNFs exhibited specific capacitance up to $150 \mathrm{~F} \mathrm{~g} \mathrm{~g}^{-1}$ and energy density up to $75 \mathrm{~W} \mathrm{~h} \mathrm{~kg}^{-1}$, respectively. Higher PAN crystallinity in precursor solution has been reported to be unfavorable to the cyclization step in PAN stabilization, producing a less uniform microstructure. To reduce PAN crystallinity and to improve cyclization reaction, $9 \mathrm{wt} \%$ vinylimidazole was introduced to PAN molecules through copolymerization. The obtained CNFs were further activated and consequently reached a high surface area of $1120 \mathrm{~m}^{2} / \mathrm{g}$. These CNFs were employed as electrodes for coin cell supercapacitors and presented specific capacitances up to $122 \mathrm{~F} \mathrm{~g}^{-1}$, and maximum energy and power densities of $47.4 \mathrm{~W} \mathrm{~h} \mathrm{~kg}^{-1}$ and $7.2 \mathrm{~kW} \mathrm{~kg}^{-1}$, respectively [53]. Recently, Yun et al. [54] fabricated hierarchically porous CNFs with the large surface area of $2862.1 \mathrm{~m}^{2} \mathrm{~g}^{-1}$, and 20.6 at $\%$ electroactive oxygen atoms. These hierarchically porous CNFs exhibited excellent electrochemical performance, and their thermal treatment with melamine results in nitrogen-doped hierarchically porous CNFs with 9.1 at $\%$ nitrogen and improved electrical properties. According to the results, the electrochemical performance of nitrogen-doped hierarchically porous CNFs is better than that of hierarchically porous CNFs, displaying a specific energy of $113 \mathrm{Wh} \mathrm{kg}^{-1}$, specific power of $105 \mathrm{~kW} \mathrm{~kg}^{-1}$, and stable cycle life of over 5000 cycles (Fig. 2a) [54]. Different morphological structures of CNFs are also presented in Figs. 1e and $f[55,56]$. Later, Tran and Kalra [57] reported the fabrication of uniformly porous CNFs for supercapacitors by using blends of PAN and sacrificial nafion. The resultant porous CNFs exhibited a specific surface area of up to $1600 \mathrm{~m}^{2} \mathrm{~g}^{-1}$ with a large fraction of mesopores $(2-4 \mathrm{~nm})$. Electrochemical measurements showed large specific gravimetric and volumetric capacitances of up to 210 $\mathrm{F} \mathrm{g} \mathrm{g}^{-1}$ and $60 \mathrm{~F} \mathrm{~cm}^{-3}$ in $1 \mathrm{M} \mathrm{H}_{2} \mathrm{SO}_{4}$ at a high cyclic voltammetry scan rate of $100 \mathrm{mV} \mathrm{s}^{-1}$ due to the large fraction of mesopores, as shown in Figs. 2b-e [57].

\subsection{Electrode material for dye-sensitized solar cells}

One-dimensional CNFs were prepared and used as a lowcost alternative to platinum counter electrodes in dye-sensitized solar cells (DSSCs) [58,59]. Electrochemical measurements revealed that the counter electrode made with CNFs exhibited low charge-transfer resistance, large surface area, and fast reaction rates in DSSCs applications. A counter electrode made of Pt/ CNFs was developed by solution-depositing Pt nanoparticles onto CNFs [60]. This type of electrode reduced the overall series resistance, decreased dark saturation current density, and the increased shunt resistance of the DSSCs. Correspondingly the $\mathrm{Pt} / \mathrm{CNF}$-based DSCs achieved an energy conversion efficiency of $\sim 8 \%$, which was improved over those of pure Pt- or pure CNFs-based DSSCs. In another research, MWCNT embedded mesoporous CNFs were prepared followed by consecutive stabilization at $280^{\circ} \mathrm{C}$, and carbonization at $800^{\circ} \mathrm{C}$. A cell using the prepared MWCNT-embedded mesoporous CNFs as a counter electrode material exhibited even higher overall energy conversion efficiency than that of the cell using a Pt counter electrode material [61]. Recently, Park et al. [59] fabricated an ACNFs hollow core/shell structure using PMMA as a pyrolytic core precursor with either PAN or PAN/PMMA blended polymer as a carbon shell precursor. The as-carbonized CNFs had a large surface area of $1191 \mathrm{~m}^{2} \mathrm{~g}^{-1}$ with a mesoporous surface area of $151 \mathrm{~m}^{2} \mathrm{~g}^{-1}$ and have shown a high efficiency of $7.21 \%$, which is comparable to a Pt counter electrode for DSSC applications (Figs. 3a and b) [59]. 

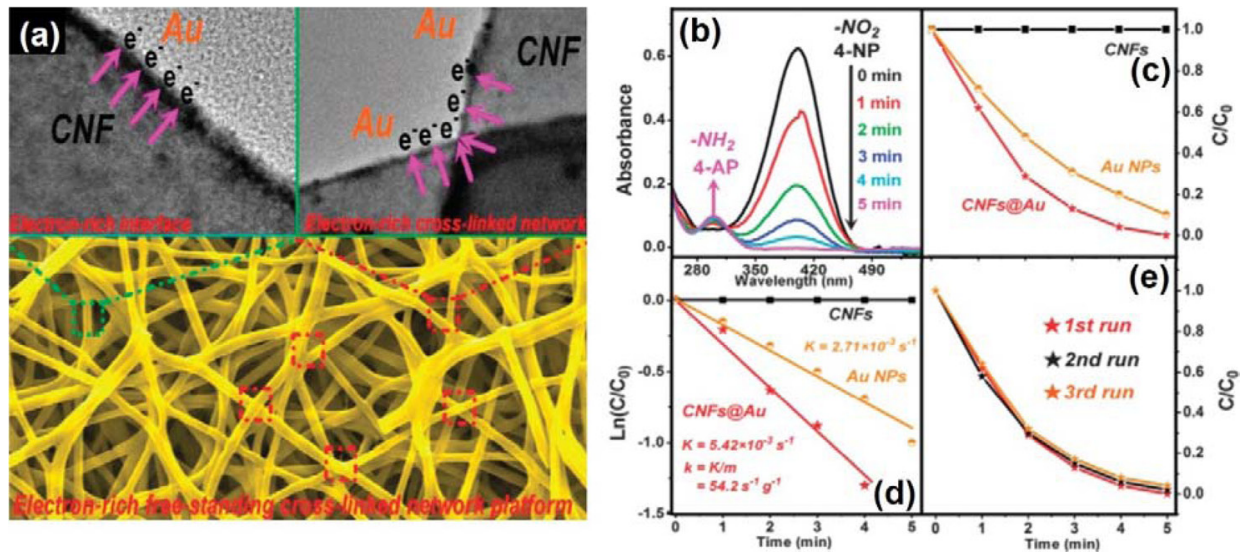

Fig. 4. (a) Schematic illustration of carbon nanofibers (CNFs)@Au as an electron-rich platform including the interface and cross-linked network. Catalytic performance of the CNFs@Au network. (b) UV-vis absorption spectra during the catalytic reduction of 4-nanoparticle over the CNFs@Au; (c and d) C/Co and $\ln \left(C / C_{0}\right)$ versus reaction times for the reduction of 4-nanoparticle, CNFs (squares), Au nanoparticles (circles) and CNFs@Au (stars); (e) catalytic activity of the CNFs@Au network for the reduction of 4-nanoparticle after three rounds of cycling. (a-e) Reprinted with permission from [73]. Copyright $\odot$ 2013, Royal Society of Chemistry.

\subsection{Anode materials for lithium-ion recharge- able batteries}

LIBs are attractive power sources for a wide range of electric devices from cell phones and laptop computers to hybrid electric vehicles. Kim et al. [21] prepared CNFs by combining electrospinning and thermal treatments. Due to the particular nanotexture, these PAN derived CNFs exhibited the highest reversible capacity (ca. $\left.450 \mathrm{~mA} \mathrm{~h} \mathrm{~g}^{-1}\right)$, and a good rate capability $(350 \mathrm{~mA}$ $\mathrm{h} \mathrm{g}^{-1}$ at a charge current of $100 \mathrm{~mA} \mathrm{~h} \mathrm{~g}^{-1}$ ) [21]. CNFs prepared from (PAN/PPy) also showed a relatively large reversible capacity (ca. $360 \mathrm{~mA} \mathrm{~h} \mathrm{~g}^{-1}$ ) with high rate capability, good cycle performance, and structural integrity after 50 charge/discharge cycles, attributable to their large surface area and extended interface with electrolyte, leading to a short pathway for charge and electron transport [62]. CNFs have also been doped with silicon and tin nanoparticles. [63] The fine dispersion of nano-sized particles within CNFs allow them to act as structural buffers, particle stabilizers, and electroactive materials, and also eliminate the need for binding or conducting additives in the electrode materials. Wang et al. [64] firstly used electrospun $\mathrm{C} / \mathrm{Si}$ composite nanofibers as an anode material for lithium ion batteries and the composite nanofibers exhibited reversible capacity $(1240 \mathrm{~mA}$ $\mathrm{h} \mathrm{g}^{-1}$ ) with stable capacity retention even after 40 cycles [64]. Yu et al. [65] prepared tin nanoparticle-dispersed carbon $(\mathrm{Sn} / \mathrm{C})$ nanofibers by stabilization of electrospun $\mathrm{SnCl}_{2} / \mathrm{PAN}$ fibers and subsequent carbonization at different temperatures. $\mathrm{Sn} / \mathrm{C}$ nanofibers at 700 and $850^{\circ} \mathrm{C}$ presented the highest charge $(785.8$ and $811 \mathrm{~mA} \mathrm{~h} \mathrm{~g}^{-1}$ ) and discharge (1211.7 and $993 \mathrm{~mA} \mathrm{~h} \mathrm{~g}^{-1}$ ) capacities due to the unique feature of reticular nanofibers geometries.

Electrospun CNFs anodes loaded with transition-metal oxide nanoparticles have been widely investigated as anode materials in lithium ion batteries, because of their high theoretical capacities, safety, non-toxicity and low cost [66]. One example is the fabrication of $\mathrm{C} / \mathrm{SnO}_{2}$ composite nanofibers with adjustable sheath thicknesses, involving the electrodeposition of $\mathrm{SnO}_{2}$ on CNFs [67]. These composite nanofibrous anodes have delivered nearly 800 $\mathrm{mA} \mathrm{h} \mathrm{g}{ }^{-1}$ discharge capacity at the first cycle at $50 \mathrm{~mA} \mathrm{~g}^{-1}$ current rate, with $69 \%$ capacity retention even after 100 charge/discharge cycles, reflecting a major improvement over pure $\mathrm{SnO}_{2}$ powderbased anodes [68]. Recently Kong et al. [69] prepared $\mathrm{C} / \mathrm{SnO}_{2} / \mathrm{C}$ core/shell/shell hybrid nanofibrous mats via single spinneret electrospinning followed by carbonization and hydrothermal treatment. The embedded and de-aggregated $\mathrm{SnO}_{2}$ nanoparticles in the carbon phase, which were less than $10 \mathrm{~nm}$ in size, provided a huge number of reaction sites for lithium ions and ensured complete alloying with them [69]. Recently, Lee et al [70] investigated the mechanical sustainability of a carbon based anode subjected to repeated electrochemical reactions with $\mathrm{Li}$ ions via nanotensile tests of individual hollow CNFs, as shown in Figs. 3c-e. Surprisingly, the mechanical properties of such electrodes were improved by repeated electrochemical reactions with $\mathrm{Li}$ ions, which is contrary to the conventional wisdom that the mechanical sustainability of carbon-based electrodes should be degraded by repeated electrochemical reactions [70].

\subsection{Catalysis}

Because of their ultra-high specific surface area, excellent electrical properties, very high chemical resistance, and acceptable mechanical properties, electrospun CNFs are materials of choice for catalytic support. For example, CNFs were developed as an electrode support for redox enzymes immobilization which is applied in bioelectrocatalytic $\mathrm{O}_{2}$ reduction. The valuable effects of these CNFs on the electrical performance of the electrode were attributed to the high loading of active enzymes and fast kinetics at the electrode surface [71]. Without any other catalyst, the porous CNFs showed high activities for nitrogen oxide (NO) removal at room temperature. In this case, carbon acted both as catalyst and adsorbent which enabled the catalytic oxidation of $\mathrm{NO}$ into $\mathrm{NO}_{2}$ or the reduction of $\mathrm{NO}$ into $\mathrm{N}_{2}$ [72]. Recently Zhang et al. [73] fabricated a 3D free-standing network composed of cross-linked carbon@Au core-shell nanofibers and the as-prepared CNFs@Au network exhibited excellent catalytic activity for the reduction of 4-nitrophenol (4-nanoparticle) based on the electron-rich catalytic platform, arising from 

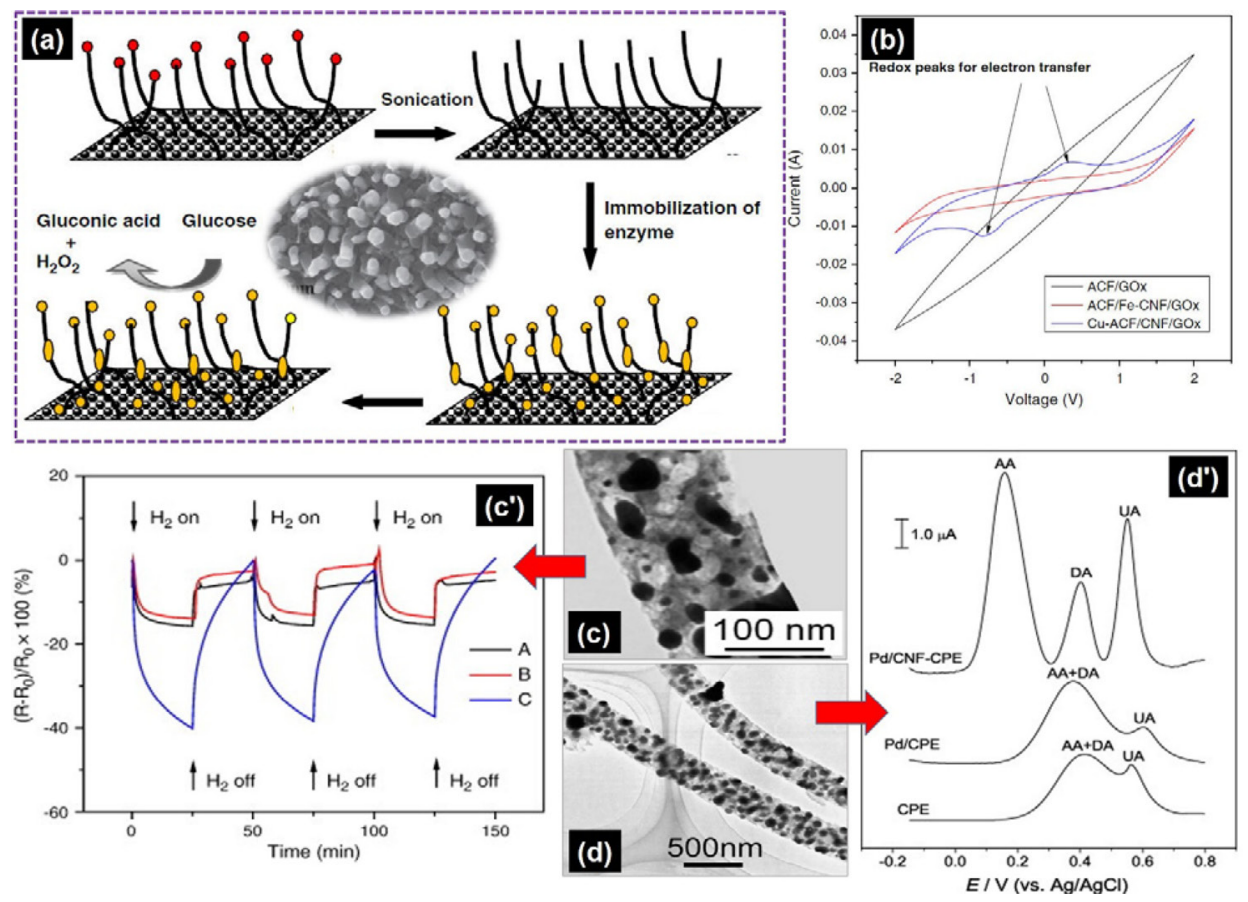

Fig. 5. (a) Schematic of the proposed bimetal carbon nanofibers (CNF)-based electrode for glucose biosensor. (b) $\mathrm{CV}$ of activated $C F(A C F) / G \mathrm{x}_{1}, \mathrm{ACF} / \mathrm{Fe}$ $\mathrm{CNF} / \mathrm{GO}_{\mathrm{x}}$, and $\mathrm{Cu}-\mathrm{ACF} / \mathrm{CNF} / \mathrm{GO}_{\mathrm{x}}$ in the presence of $2 \mathrm{mM}$ glucose (scan rate $\left.=100 \mathrm{mV} / \mathrm{s}\right)$. Transmission electron microscope (TEM) image of the as-prepared (c) $\mathrm{Pd} / \mathrm{CNF}$ nanocomposites and (c') response curves of different carbon nano-felts upon exposure to $\mathrm{H}_{2}$ at room temperature. (d) TEM image of ASFPAN-PdNP and (d') DPVs at bare carbon paste electrode (CPE), Pd/CPE and Pd/CNF-CPE in $0.1 \mathrm{M}$ PBS (pH 4.5) containing $2 \mathrm{mM}$ ascorbic acid, $50 \mu \mathrm{M}$ dopamine and 100 $\mu \mathrm{M}$ uric acid. (a and b) Reprinted with permission from [80]. Copyright $\odot$ 2013, Elsevier. (c and c') Reprinted with permission from [86]. Copyright $\odot$ 2012, Elsevier. (d and d') Reprinted with permission from [55]. Copyright $\odot 2008$, Elsevier.

the synergistic effect between carbon and Au. Notably, the freestanding 3D nanofibrous cross-linked network structure could improve the catalyst's separation and reuse (Figs. 4a-e) [73]. Composite $\mathrm{Pd}$ and $\mathrm{Pt} / \mathrm{CNF}$ s with nanocactus- and nanoflowerlike morphology were fabricated to act as a highly active catalyst toward the redox reactions of hydrogen peroxide $\left(\mathrm{H}_{2} \mathrm{O}_{2}\right)$ and $\beta$-nicotinamide adenine dinucleotide [74]. Carbon/Ag nanoparticles composite nanofibers have also shown high catalytic activity in the reduction of 4-nitrophenol with $\mathrm{NaBH}_{4}$ which might be attributed to the high surface areas of Ag nanoparticles loaded on the CNFs and the synergistic effect on delivery of electrons between Ag nanoparticles and CNFs [75]. One dimensional $\mathrm{ZnO} / \mathrm{CNFs}$ with high photocatalytic activity were successfully prepared to degrade organic pollutants under UV light irradiation [76]. It was demonstrated that CNFs with surface-coated $\mathrm{ZnO}$ exhibited higher photocatalytic property than pure $\mathrm{ZnO}$ for the degradation of Rhodamine $\mathrm{B}$. In later research, 1D heterostructures of $\mathrm{Bi}_{2} \mathrm{MoO}_{6} / \mathrm{CNFs}$ and $\operatorname{In}_{2} \mathrm{O}_{3} / \mathrm{CNFs}$ were fabricated to use in various catalytic activities [77]. Enhanced photocatalytic activity was perceived for those hetero-structures under visible light compared to pure $\mathrm{Bi}_{2} \mathrm{MoO}_{6}$ or $\operatorname{In}_{2} \mathrm{O}_{3}$.

\subsection{Sensors}

Sensors/detectors with suitable operation, simple construction, steady response, high sensitivity, with good selectivity are always required for the determination of various chemicals and biomolecules. CNFs modified carbon paste electrode (CNF-
CPE) was developed by casting a water suspension of CNFs onto the surface of a CPE and such electrodes were used to directly detect the three amino acids 1-tryptophan, 1-tyrosine, and l-cysteine using cyclic voltammetry and constant potential amperometric methods [78]. The modified electrodes have shown excellent electrocatalytic activity and good analytical performance toward the oxidation of amino acids with a detection limit of $0.1 \mu \mathrm{M}$. CNF-CPE was also used to build an amperometric sensor device without any enzyme or medium to detect xanthine (Xa) [79]. The dynamic linear range of Xa detection was 0.03 to $21.19 \mu \mathrm{M}$ with a detection limit as low as $20 \mathrm{nM}$. The system was effectively applied to estimate the freshness of fish and determine Xa in human urine. Recently, Hood et al. described the development of a bimetal ( $\mathrm{Fe}$ and $\mathrm{Cu}$ )-grown hierarchical web of CNFs electrode for glucose sensing applications, with a sensitivity of $8.29 \mu \mathrm{A} / \mathrm{mM} \mathrm{cm}^{-2}$ and a linearity up to $8.5 \mathrm{mM}\left(\mathrm{R}^{2}=\right.$ 0.991) (Figs. 5a and b) [80].

For bio sensing applications, carboxylic acid group functionalized CNFs were combined with other nanostructures to fabricate composite electrodes, and then used to incorporate hydroxyapatite (HA) or prussian blue to make a composite. These composites were coated on a polished $\mathrm{Au}$ electrode followed by immobilization of cytochrome $\mathrm{c}$. The resulting biosensor established a good electrocatalytic activity and fast response to $\mathrm{H}_{2} \mathrm{O}_{2}$ sensing, with a detection limit of $0.3 \mu \mathrm{M}$ [81]. Beside pure CNFs, metal nanoparticle-loaded CNFs could also be used to modify electrodes; for example, Pd nanoparticle-loaded-loaded CNFs was used to coat CPE (Figs. 5d and d') [55]. The as-modified 

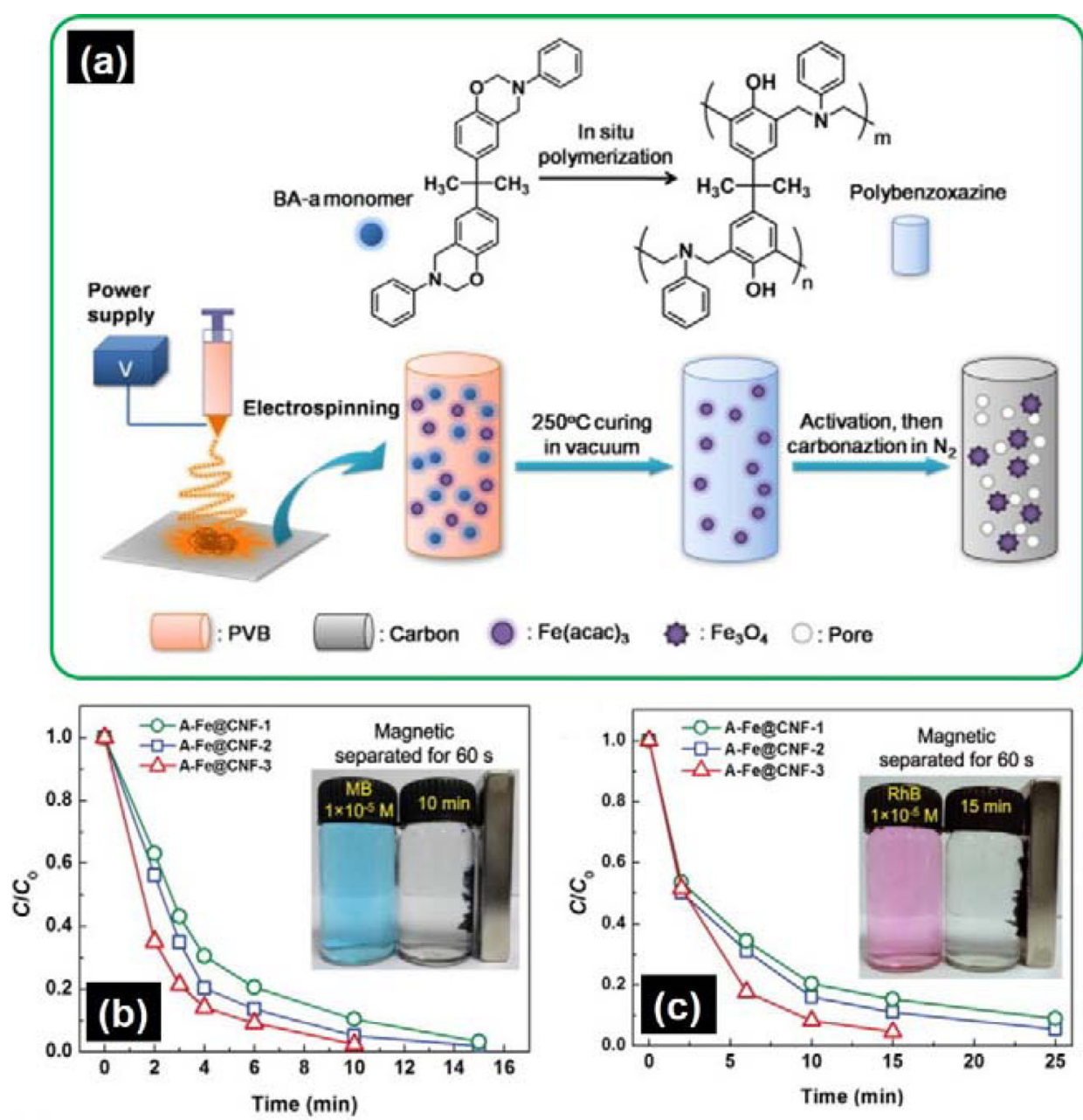

Fig. 6. (a) Illustration showing the synthesis of A-Fe@carbon nanofiber (CNF) by a combination of electrospinning and in situ polymerization. The C/Co versus time plots for adsorption of (c) methylene blue (MB) and (d) rhodamine B (RhB) dye solution. The insets show the magnetic responsive performance (60 s) of A-Fe@CNF-3 after adsorption of MB (10 min) and RhB (15 min). (a-c) Reprinted with permission from [92]. Copyright $\odot$ 2012, Elsevier.

electrode exhibited excellent electrochemical catalytic activities toward dopamine (DA), uric acid (UA), and ascorbic acid (AA), which frequently coexist in biological samples, by decreasing their oxidation overpotentials and improving their peak currents. The lowest detection limits of DA, UA, and AA were observed at $0.2,0.7,15 \mu \mathrm{M}$, respectively. Similarly rhodium nanoparticleloaded CNFs were dispersed in DMF under ultrasonic agitation and then cast on the surface of a pretreated pyrolytic graphite electrode. The as-modified electrode established excellent electrocatalytic activity toward hydrazine oxidation [82]. In a more recent research, a cobalt nanoparticles-decorated CNFs modified electrode showed a $\mathrm{pH}$-controlled electrocatalytic activity toward the oxidation of cysteine and $\mathrm{N}$-acetyl cysteine, which was used to fabricate an enzymeless sensor for amino acid [83].

In addition to the electrochemical detection of chemicals, CNFs can detect gases through resistance change. Ultrafine $\mathrm{CNF}$ s decorated with $\mathrm{ZnO} / \mathrm{SnO}_{2}$ nanoparticles were deposited on an interdigitated electrode array and constructed to detect dimethyl methylphosphonate with a minimum detectable level of $0.1 \mathrm{ppb}$ [84]. Recently, CNFs attached with Pd nanoparticles have shown excellent hydrogen sensing capability at room tem- perature [85]. Pd nanoparticles could be alternatively deposited on $\mathrm{CNFs}$ via supercritical $\mathrm{CO}_{2}$ method for the sensing of hydrogen (Figs. 5c and c') [86].

\subsection{Adsorption/separation}

Carbon materials, particularly activated carbons, have been used as a powerful adsorbent for a long time [87-89]. Lee at al. [90] demonstrated that the ACNFs possess superior capability for formaldehyde gas adsorption even at a low concentration and in a humid environment. ACNFs have also been actively used as an effective tool to remove NO in polluted air [71]. The reported percentage of $\mathrm{NO}$ removed by $0.1 \mathrm{~g}$ of porous CNFs material was higher than $60 \%$ when inlet NO concentration was $20 \mathrm{ppm}$. CNFs adsorption media have also been used as a promising alternative for bioseparation. Surface-functionalized CNFs with weak acid cation exchange ligand were capable of adsorbing approximately ten-times more protein than their microfiber counterparts [91]. Recently, magnetic $\mathrm{Fe}_{3} \mathrm{O}_{4}$ loaded CNFs based on PBZ precursors have been synthesized by a combination of electrospinning and in situ polymerization. The benzoxazine 

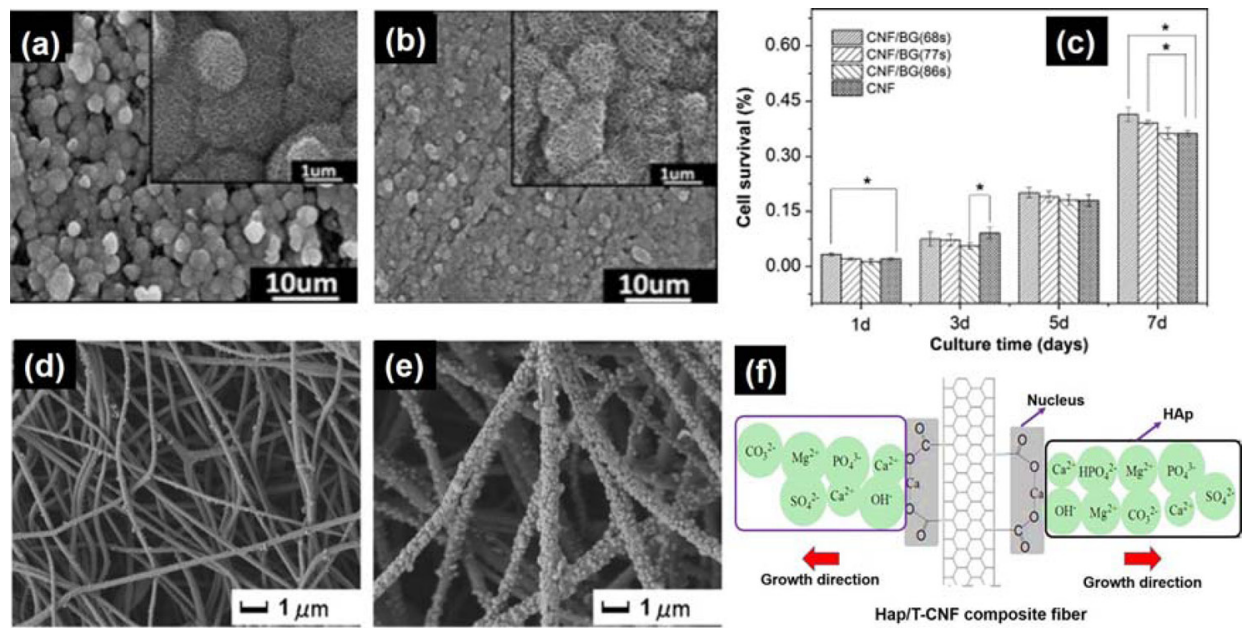

Fig. 7. Scanning electron microscope (SEM) micrographs obtained for the carbon nanofiber (CNF)/bioactive glass (BG) after being soaked in 1.5 SBF at $37^{\circ} \mathrm{C}$ for 4 days (a) and 6 days (b). (c) Proliferation of MC3T3-E1 osteoblasts on different CNF/BG composite membranes in comparison with pure CNF assessed using CCK-8 assay. (e) SEM images of (d) 1 h-T-CNF/hydroxyapatite (HA) and (e) 6 h-T-CNF/HA, and (c) growth of HA on activated CNFs. (a-c) Reprinted with permission from [96]. Copyright $\odot$ 2013, Elsevier. (d-f) Reprinted with permission from [58]. Copyright @ 2013, Elsevier.

monomers could effortlessly form thermosetting nanofibers by in situ ring-opening polymerization, and subsequently be converted into CNFs by carbonization (Fig. 6). The resultant fibers with an average diameter of $130 \mathrm{~nm}$ are comprised of CNFs with embedded $\mathrm{Fe}_{3} \mathrm{O}_{4}$ nanocrystals, and could have a high surface area of $1885 \mathrm{~m}^{2} \mathrm{~g}^{-1}$ and a porosity of $2.3 \mathrm{~cm}^{3} \mathrm{~g}^{-1}$. The $\mathrm{Fe}_{3} \mathrm{O}_{4}$ loaded CNFs exhibited efficient adsorption for organic dyes in water and excellent magnetic separation performance, suggesting their use as a promising adsorbent for water treatment, and also provided new insight into the design and development of a carbon nanomaterial based on a PBZ precursor [92].

\subsection{Biomedical application}

The application of carbon fibers in the biomedical field has a history of more than 30 years to date $[93,94]$. CNFs containing $\beta$-tricalcium phosphate nanoparticles have shown good biocompatibility for cell growth [95]. The results indicated that bioactive HA strongly interacted with the CNFs through coordination bonds and would provide strong interfacial bonding to host tissues. Fracture strength of the CNFs/HA composite reached 67.3 MPa with $41.3 \% \mathrm{CNFs}$. Bioactive glass (BG) is a bioceramic that has been investigated for applications in bone regeneration. CNFs with $\mathrm{BG}$ were developed as a substrate for bone regeneration uses. Biomineralization in simulated body fluid and in vitro co-culture with MC3T3-E1 osteoblasts revealed the improved ability of $\mathrm{CNFs} / \mathrm{BG}$ composites to promote the in vitro formation of apatite and MC3T3-E1 proliferation (Figs. 7a-c) [96]. Natural bone is a fiber-reinforced hybrid material composed of type-I collagen fibers and HA minerals. CNFs were also used to prepare a CNFs/HA composite to mimic the collagen fiber/HA composite structure of natural bone (Figs. 7d-f) [56]. The fracture strength of the CNF/HA composite with a CNF content of $41.3 \%$ reached $67.3 \mathrm{MPa}$. $\mathrm{CNF} / \mathrm{HA}$ composites with such strong interfacial bonding and high mechanical strength can be potentially useful in the field of bone tissue engineering.

\section{Concluding Remarks and Future Perspectives}

CNFs having diameters intermediate between CNTs and carbon fibers with hierarchical pore structures can be conveniently fabricated by electrospinning polymeric precursors followed by stabilization and carbonization. This new class of carbon nanomaterial with 1D nanostructure and associated high specific surface area has rapidly found application in energy conversion and storage, catalysis, sensor, adsorption, and biomedical fields. However, few studies have focused on the stretching of electrospun precursor nanofibers before stabilization, and tension is rarely applied to the nanofibers assembly during stabilization to prevent shrinkage of the fibers and to ensure a large degree of molecular orientations along the fiber axis. Therefore, there is still considerable room for further improvement of the microstructural, electrical and mechanical properties of the final CNFs. Current attempts reveal there is a strong expectation of achieving even higher strength carbon fibers. Future research will be focused on the fundamental correlations between processing conditions and the nanofibers' structures and it is envisioned that electrospun continuous CNFs are going to contribute greatly to the emerging family of carbon materials.

\section{Acknowledgments}

This work is supported by the National Natural Science Foundation of China (No. U1232116) and the Fundamental Research Funds for the Central Universities.

\section{References}

[1] Fitzer E, Gkogkidis A, Heine M. Carbon fibres and their composites (a review). High Temp High Press, 16, 363 (1984).

[2] Iijima S. Helical microtubules of graphitic carbon. Nature, 354, 56 
(1991). http://dx.doi.org/10.1038/354056a0.

[3] Liu L, He P, Zhou K, Chen T. Microwave absorption properties of helical carbon nanofibers-coated carbon fibers. AIP Adv, 3, 082112 (2013). http://dx.doi.org/10.1063/1.4818495.

[4] Baker RTK. Catalytic growth of carbon filaments. Carbon, 27, 315 (1989). http://dx.doi.org/10.1016/0008-6223(89)90062-6.

[5] Cooley JF. Apparatus for electrically dispersing fluids. US Patent 692631 (1902).

[6] Huang C, Soenen SJ, Rejman J, Lucas B, Braeckmans K, Demeester J, De Smedt SC. Stimuli-responsive electrospun fibers and their applications. Chem Soc Rev, 40, 2417 (2011). http://dx.doi. org/10.1039/C0CS00181C.

[7] Wang X, Ding B, Sun G, Wang M, Yu J. Electro-spinning/netting: a strategy for the fabrication of three-dimensional polymer nano-fiber/nets. Prog Mater Sci, 58, 1173 (2013). http://dx.doi. org/10.1016/j.pmatsci.2013.05.001.

[8] Shang Y, Si Y, Raza A, Yang L, Mao X, Ding B, Yu J. An in situ polymerization approach for the synthesis of superhydrophobic and superoleophilic nanofibrous membranes for oil-water separation. Nanoscale, 4, 7847 (2012). http://dx.doi.org/10.1039/ C2NR33063F.

[9] Wang J, Raza A, Si Y, Cui L, Ge J, Ding B, Yu J. Synthesis of superamphiphobic breathable membranes utilizing $\mathrm{SiO}_{2}$ nanoparticles decorated fluorinated polyurethane nanofibers. Nanoscale, $\mathbf{4}$, 7549 (2012). http://dx.doi.org/10.1039/C2NR32883F.

[10] Yang L, Raza A, Si Y, Mao X, Shang Y, Ding B, Yu J, Al-Deyab SS. Synthesis of superhydrophobic silica nanofibrous membranes with robust thermal stability and flexibility via in situ polymerization. Nanoscale, 4, 6581 (2012). http://dx.doi.org/10.1039/ C2NR32095A.

[11] Dersch R, Steinhart M, Boudriot U, Greiner A, Wendorff JH. Nanoprocessing of polymers: applications in medicine, sensors, catalysis, photonics. Polym Adv Technol, 16, 276 (2005). http:// dx.doi.org/10.1002/pat.568.

[12] Ding B, Wang M, Wang X, Yu J, Sun G. Electrospun nanomaterials for ultrasensitive sensors. Mater Today, 13, 16 (2010). http:/ dx.doi.org/10.1016/S1369-7021(10)70200-5.

[13] Ra EJ, An KH, Kim KK, Jeong SY, Lee YH. Anisotropic electrical conductivity of MWCNT/PAN nanofiber paper. Chem Phys Lett, 413, 188 (2005). http://dx.doi.org/10.1016/j.cplett.2005.07.061.

[14] Zhang L, Hsieh YL. Nanoporous ultrahigh specific surface polyacrylonitrile fibres. Nanotechnology, 17, 4416 (2006). http://dx.doi. org/10.1088/0957-4484/17/17/022.

[15] Kong QQ, Yang MG, Chen CM, Yang YG, Wen YF, Wang MZ. Preparation and characterization of graphene-reinforced polyacrylonitrile-based carbon nanofibers. New Carbon Mater, 27, 188 (2012).

[16] Wu M, Wang Q, Li K, Wu Y, Liu H. Optimization of stabilization conditions for electrospun polyacrylonitrile nanofibers. Polym Degradation Stab, 97, 1511 (2012). http://dx.doi.org/10.1016/j. polymdegradstab.2012.05.001.

[17] Zhang L, Hsieh YL. Carbon nanofibers with nanoporosity and hollow channels from binary polyacrylonitrile systems. Eur Polym J, 45, 47 (2009). http://dx.doi.org/10.1016/j.eurpolymj.2008.09.035.

[18] Wang Y, Serrano S, Santiago-Avilés JJ. Raman characterization of carbon nanofibers prepared using electrospinning. Synth Met, 138, 423 (2003). http://dx.doi.org/10.1016/S0379-6779(02)00472-1.

[19] Wang Y, Santiago-Avilés JJ. Large negative magnetoresistance and two-dimensional weak localization in carbon nanofiber fabricated using electrospinning. J Appl Phys, 94, 1721 (2003). http://dx.doi. org/10.1063/1.1587268.

[20] Zussman E, Chen X, Ding W, Calabri L, Dikin DA, Quintana JP, Ruoff RS. Mechanical and structural characterization of electrospun PAN-derived carbon nanofibers. Carbon, 43, 2175 (2005). http://dx.doi.org/10.1016/j.carbon.2005.03.031.

[21] Kim C, Yang KS, Kojima M, Yoshida K, Kim YJ, Kim YA, Endo M. Fabrication of electrospinning-derived carbon nanofiber webs for the anode material of lithium-ion secondary batteries. Adv Funct Mater, 16, 2393 (2006). http://dx.doi.org/10.1002/ adfm. 200500911.

[22] Kim C, Yang KS. Electrochemical properties of carbon nanofiber web as an electrode for supercapacitor prepared by electrospinning. Appl Phys Lett, 83, 1216 (2003). http://dx.doi.org/ 10.1063/1.1599963.

[23] Prilutsky S, Zussman E, Cohen Y. The effect of embedded carbon nanotubes on the morphological evolution during the carbonization of poly(acrylonitrile) nanofibers. Nanotechnology, 19, 165603 (2008). http://dx.doi.org/10.1088/0957-4484/19/16/165603.

[24] Ko F, Gogotsi Y, Ali A, Naguib N, Ye H, Yang GL, Li C, Willis P. Electrospinning of continuous carbon nanotube-filled nanofiber yarns. Adv Mater, 15, 1161 (2003). http://dx.doi.org/10.1002/ adma.200304955.

[25] Kim S, Lim SK. Preparation of $\mathrm{TiO}_{2}$-embedded carbon nanofibers and their photocatalytic activity in the oxidation of gaseous acetaldehyde. Appl Catal B, 84, 16 (2008). http://dx.doi.org/10.1016/j. apcatb.2008.02.025.

[26] Oh GY, Ju YW, Jung HR, Lee WJ. Preparation of the novel manganese-embedded PAN-based activated carbon nanofibers by electrospinning and their toluene adsorption. J Anal Appl Pyrolysis, 81, 211 (2008). http://dx.doi.org/10.1016/j.jaap.2007.11.006.

[27] Si Y, Ren T, Ding B, Yu J, Sun G. Synthesis of mesoporous magnetic $\mathrm{Fe}_{3} \mathrm{O}_{4} @$ carbon nanofibers utilizing in situ polymerized polybenzoxazine for water purification. J Mater Chem, 22, 4619 (2012). http://dx.doi.org/10.1039/C2JM00036A.

[28] Ren T, Si Y, Yang J, Ding B, Yang X, Hong F, Yu J. Polyacrylonitrile/polybenzoxazine-based $\mathrm{Fe}_{3} \mathrm{O}_{4} @$ carbon nanofibers: hierarchical porous structure and magnetic adsorption property. J Mater Chem, 22, 15919 (2012). http://dx.doi.org/10.1039/C2JM33214K.

[29] Ju YW, Choi GR, Jung HR, Lee WJ. Electrochemical properties of electrospun PAN/MWCNT carbon nanofibers electrodes coated with polypyrrole. Electrochim Acta, 53, 5796 (2008). http://dx.doi. org/10.1016/j.electacta.2008.03.028.

[30] Shao D, Wei Q, Zhang L, Cai Y, Jiang S. Surface functionalization of carbon nanofibers by sol-gel coating of zinc oxide. Appl Surf Sci, 254, 6543 (2008). http://dx.doi.org/10.1016/j.apsusc.2008.04.055.

[31] Shin J, Ryu WH, Park KS, Kim ID. Morphological evolution of carbon nanofibers encapsulating SnCo alloys and its effect on growth of the solid electrolyte interphase layer. ACS Nano, 7, 7330 (2013). http://dx.doi.org/10.1021/nn403003b.

[32] Cheng Y, Li T, Fang C, Zhang M, Liu X, Yu R, Hu J. Soft-templated synthesis of mesoporous carbon nanospheres and hollow carbon nanofibers. Appl Surf Sci, 282, 862 (2013). http://dx.doi org/10.1016/j.apsusc.2013.06.072.

[33] Kim BJ, Kil H, Watanabe N, Seo MH, Kim BH, Yang KS, Kato O, Miyawaki J, Mochida I, Yoon SH. Preparation of novel isotropic pitch with high softening point and solvent solubility for pitchbased electrospun carbon nanofiber. Curr Org Chem, 17, 1463 (2013). http://dx.doi.org/10.2174/1385272811317130013. 
[34] Park SH, Kim C, Choi YO, Yang KS. Preparations of pitch-based CF/ACF webs by electrospinning. Carbon, 41, 2655 (2003). http:// dx.doi.org/10.1016/S0008-6223(03)00272-0.

[35] Park SH, Kim C, Jeong YI, Lim DY, Lee YE, Yang KS. Activation behaviors of isotropic pitch-based carbon fibers from electrospinning and meltspinning. Synth Met, 146, 207 (2004). http://dx.doi. org/10.1016/j.synthmet.2004.07.004.

[36] Zhu Y, Zhang JC, Zhai J, Zheng YM, Feng L, Jiang L. Multifunctional carbon nanofibers with conductive, magnetic and superhydrophobic properties. Chemphyschem, 7, 336 (2006). http://dx.doi. org/10.1002/cphc.200500407.

[37] Xuyen NT, Ra EJ, Geng HZ, Kim KK, An KH, Lee YH. Enhancement of conductivity by diameter control of polyimide-based electrospun carbon nanofibers. J Phys Chem B, 111, 11350 (2007). http://dx.doi.org/10.1021/jp075541q.

[38] Smirnova VE, Gofman IV, Ivan'kova EM, Didenko AL, Krestinin AV, Zvereva GI, Svetlichnyi VM, Yudin VE. Effect of singlewalled carbon nanotubes and carbon nanofibers on the structure and mechanical properties of thermoplastic polyimide matrix films. Polym Sci Ser A, 55, 268 (2013). http://dx.doi.org/10.1134/ S0965545X1304007X

[39] Seki N, Arai T, Suzuki Y, Kawakami H. Novel polyimide-based electrospun carbon nanofibers prepared using ion-beam irradiation. Polymer, 53, 2062 (2012). http://dx.doi.org/10.1016/j.polymer.2012.03.026.

[40] Kim C, Choi YO, Lee WJ, Yang KS. Supercapacitor performances of activated carbon fiber webs prepared by electrospinning of PMDA-ODA poly(amic acid) solutions. Electrochim Acta, 50, 883 (2004). http://dx.doi.org/10.1016/j.electacta.2004.02.072.

[41] Chung GS, Jo SM, Kim BC. Properties of carbon nanofibers prepared from electrospun polyimide. J Appl Polym Sci, 97, 165 (2005). http://dx.doi.org/10.1002/app.21742.

[42] Kim C, Kim YJ, Kim YA. Fabrication and structural characterization of electro-spun polybenzimidazol-derived carbon nanofiber by graphitization. Solid State Commun, 132, 567 (2004). http:// dx.doi.org/10.1016/j.ssc.2004.08.035.

[43] Okuzaki H, Takahashi T, Hara Y, Yan H. Uniaxially aligned carbon nanofibers derived from electrospun precursor yarns. J Polym Sci B, 46, 305 (2008). http://dx.doi.org/10.1002/polb.21368.

[44] Iijima S, Ichihashi T. Single-shell carbon nanotubes of 1-nm diameter. Nature, 363, 603 (1993). http://dx.doi.org/10.1038/363603a0.

[45] Kim C, Yang KS, Lee WJ. The use of carbon nanofiber electrodes prepared by electrospinning for electrochemical supercapacitors. Electrochem Solid-State Lett, 7, A397 (2004). http://dx.doi. org/10.1149/1.1801631.

[46] Inagaki M, Konno H, Tanaike O. Carbon materials for electrochemical capacitors. J Power Sources, 195, 7880 (2010). http:// dx.doi.org/10.1016/j.jpowsour.2010.06.036.

[47] Ju YW, Park SH, Jung HR, Lee WJ. Electrospun activated carbon nanofibers electrodes based on polymer blends. J Electrochem Soc, 156, A489 (2009). http://dx.doi.org/10.1149/1.3116245.

[48] Guo Q, Zhou X, Li X, Chen S, Seema A, Greiner A, Hou H. Supercapacitors based on hybrid carbon nanofibers containing multiwalled carbon nanotubes. J Mater Chem, 19, 2810 (2009). http:// dx.doi.org/10.1039/B820170F

[49] Kim BH, Kim CH, Yang KS, Rahy A, Yang DJ. Electrospun vanadium pentoxide/carbon nanofiber composites for supercapacitor electrodes. Electrochim Acta, 83, 335 (2012). http://dx.doi. org $/ 10.1016 / j$.electacta.2012.07.093
[50] Kim BH, Yang KS, Woo HG. Boron-nitrogen functional groups on porous nanocarbon fibers for electrochemical supercapacitors. Mater Lett, 93, 190 (2013). http://dx.doi.org/10.1016/j.matlet.2012.11.057

[51] Zhou Z, Wu XF. Graphene-beaded carbon nanofibers for use in supercapacitor electrodes: Synthesis and electrochemical characterization. J Power Sources, 222, 410 (2013). http://dx.doi org/10.1016/j.jpowsour.2012.09.004.

[52] Kim BH, Yang KS, Ferraris JP. Highly conductive, mesoporous carbon nanofiber web as electrode material for high-performance supercapacitors. Electrochim Acta, 75, 325 (2012). http://dx.doi org/10.1016/j.electacta.2012.05.004.

[53] Jung KH, Deng W, Smith DW, Jr., Ferraris JP. Carbon nanofiber electrodes for supercapacitors derived from new precursor polymer: poly(acrylonitrile-co-vinylimidazole). Electrochem Commun, 23, 149 (2012). http://dx.doi.org/10.1016/j.elecom.2012.07.026.

[54] Yun YS, Im C, Park HH, Hwang I, Tak Y, Jin HJ. Hierarchically porous carbon nanofibers containing numerous heteroatoms for supercapacitors. J Power Sources, 234, 285 (2013). http://dx.doi. org/10.1016/j.jpowsour.2013.01.169.

[55] Huang J, Liu Y, Hou H, You T. Simultaneous electrochemical determination of dopamine, uric acid and ascorbic acid using palladium nanoparticle-loaded carbon nanofibers modified electrode. Biosensors Bioelectron, 24, 632 (2008). http://dx.doi.org/10.1016/j. bios.2008.06.011.

[56] Wu M, Wang Q, Liu X, Liu H. Biomimetic synthesis and characterization of carbon nanofiber/hydroxyapatite composite scaffolds. Carbon, 51, 335 (2013). http://dx.doi.org/10.1016/j.carbon. 2012.08.061.

[57] Tran C, Kalra V. Fabrication of porous carbon nanofibers with adjustable pore sizes as electrodes for supercapacitors. J Power Sources, 235, 289 (2013). http://dx.doi.org/10.1016/j.jpowsour. 2013.01.080.

[58] Yousef A, Akhtar MS, Barakat NAM, Motlak M, Yang OB, Kim HY. Effective NiCu NPs-doped carbon nanofibers as counter electrodes for dye-sensitized solar cells. Electrochim Acta, 102, 142 (2013). http://dx.doi.org/10.1016/j.electacta.2013.04.013

[59] Park SH, Kim BK, Lee WJ. Electrospun activated carbon nanofibers with hollow core/highly mesoporous shell structure as counter electrodes for dye-sensitized solar cells. J Power Sources, 239, 122 (2013). http://dx.doi.org/10.1016/j.jpowsour.2013.03.079.

[60] Poudel P, Zhang L, Joshi P, Venkatesan S, Fong H, Qiao Q. Enhanced performance in dye-sensitized solar cells via carbon nanofibers-platinum composite counter electrodes. Nanoscale, 4, 4726 (2012). http://dx.doi.org/10.1039/C2NR30586K.

[61] Park SH, Jung HR, Kim BK, Lee WJ. MWCNT/mesoporous carbon nanofibers composites prepared by electrospinning and silica template as counter electrodes for dye-sensitized solar cells. J Photochem Photobiol A, 246, 45 (2012). http://dx.doi.org/10.1016/j. jphotochem.2012.07.013.

[62] Ji L, Yao Y, Toprakci O, Lin Z, Liang Y, Shi Q, Medford AJ, Millns CR, Zhang X. Fabrication of carbon nanofiber-driven electrodes from electrospun polyacrylonitrile/polypyrrole bicomponents for high-performance rechargeable lithium-ion batteries. J Power Sources, 195, 2050 (2010). http://dx.doi.org/10.1016/j.jpowsour. 2009.10.021.

[63] Zou L, Gan L, Kang F, Wang M, Shen W, Huang Z. Sn/C nonwoven film prepared by electrospinning as anode materials for lithium ion batteries. J Power Sources, 195, 1216 (2010). http:// 
dx.doi.org/10.1016/j.jpowsour.2009.08.052.

[64] Wang L, Ding CX, Zhang LC, Xu HW, Zhang DW, Cheng T, Chen $\mathrm{CH}$. A novel carbon-silicon composite nanofiber prepared via electrospinning as anode material for high energy-density lithium ion batteries. J Power Sources, 195, 5052 (2010). http://dx.doi. org/10.1016/j.jpowsour.2010.01.088.

[65] Yu Y, Yang Q, Teng D, Yang X, Ryu S. Reticular Sn nanoparticledispersed PAN-based carbon nanofibers for anode material in rechargeable lithium-ion batteries. Electrochem Commun, 12, 1187 (2010). http://dx.doi.org/10.1016/j.elecom.2010.06.015.

[66] Zhang P, Guo ZP, Huang Y, Jia D, Liu HK. Synthesis of $\mathrm{Co}_{3} \mathrm{O}_{4} /$ carbon composite nanowires and their electrochemical properties. J Power Sources, 196, 6987 (2011). http://dx.doi.org/10.1016/j. jpowsour.2010.10.090.

[67] Meschini I, Nobili F, Mancini M, Marassi R, Tossici R, Savoini A, Focarete ML, Croce F. High-performance Sn@carbon nanocomposite anode for lithium batteries. J Power Sources, 226, 241 (2013). http://dx.doi.org/10.1016/j.jpowsour.2012.11.004

[68] Zou L, Gan L, Lv R, Wang M, Huang ZH, Kang F, Shen W. A film of porous carbon nanofibers that contain $\mathrm{Sn} / \mathrm{SnOx}$ nanoparticles in the pores and its electrochemical performance as an anode material for lithium ion batteries. Carbon, 49, 89 (2011). http://dx.doi. org/10.1016/j.carbon.2010.08.046.

[69] Kong J, Liu Z, Yang Z, Tan HR, Xiong S, Wong SY, Li X, Lu $\mathrm{X}$. Carbon $/ \mathrm{SnO}_{2} /$ carbon core/shell/shell hybrid nanofibers: tailored nanostructure for the anode of lithium ion batteries with high reversibility and rate capacity. Nanoscale, 4, 525 (2012). http:// dx.doi.org/10.1039/C1NR10962F.

[70] Lee BS, Seo JH, Son SB, Kim SC, Choi IS, Ahn JP, Oh KH, Lee $\mathrm{SH}, \mathrm{Yu}$ WR. Face-centered-cubic lithium crystals formed in mesopores of carbon nanofiber electrodes. ACS Nano, 7, 5801 (2013). http://dx.doi.org/10.1021/nn4019625.

[71] Wang MX, Huang ZH, Shimohara T, Kang F, Liang K. NO removal by electrospun porous carbon nanofibers at room temperature. Chem Eng J, 170, 505 (2011). http://dx.doi.org/10.1016/j. cej.2011.01.017.

[72] Wang MX, Huang ZH, Shen K, Kang F, Liang K. Catalytically oxidation of $\mathrm{NO}$ into $\mathrm{NO}_{2}$ at room temperature by graphitized porous nanofibers. Catal Today, 201, 109 (2013). http://dx.doi. org/10.1016/j.cattod.2012.05.050.

[73] Zhang P, Shao C, Li X, Zhang M, Zhang X, Su C, Lu N, Wang K, Liu Y. An electron-rich free-standing carbon@Au core-shell nanofiber network as a highly active and recyclable catalyst for the reduction of 4-nitrophenol. Phys Chem Chem Phys, 15, 10453 (2013). http://dx.doi.org/10.1039/C3CP50917F.

[74] Lin Z, Ji L, Medford A, Shi Q, Krause W, Zhang X. Electrocatalytic interaction of nano-engineered palladium on carbon nanofibers with hydrogen peroxide and $\beta$-NADH. J Solid State Electrochem, 15, 1287 (2011). http://dx.doi.org/10.1007/s10008-010-1218-2.

[75] Zhang P, Shao C, Zhang Z, Zhang M, Mu J, Guo Z, Liu Y. In situ assembly of well-dispersed Ag nanoparticles (AgNPs) on electrospun carbon nanofibers (CNFs) for catalytic reduction of 4-nitrophenol. Nanoscale, 3, 3357 (2011). http://dx.doi.org/10.1039/ C1NR10405E

[76] Mu J, Shao C, Guo Z, Zhang Z, Zhang M, Zhang P, Chen B, Liu Y. High photocatalytic activity of $\mathrm{ZnO}-$ carbon nanofiber heteroarchitectures. ACS Appl Mater Interfaces, 3, 590 (2011). http://dx.doi. org/10.1021/am101171a.

[77] Zhang M, Shao C, Mu J, Huang X, Zhang Z, Guo Z, Zhang P, Liu
Y. Hierarchical heterostructures of $\mathrm{Bi}_{2} \mathrm{MoO}_{6}$ on carbon nanofibers: controllable solvothermal fabrication and enhanced visible photocatalytic properties. J Mater Chem, 22, 577 (2012). http://dx.doi. org/10.1039/C1JM13470A.

[78] Tang X, Liu Y, Hou H, You T. Electrochemical determination of L-tryptophan, L-tyrosine and L-cysteine using electrospun carbon nanofibers modified electrode. Talanta, 80, 2182 (2010). http:// dx.doi.org/10.1016/j.talanta.2009.11.027.

[79] Tang X, Liu Y, Hou H, You T. A nonenzymatic sensor for xanthine based on electrospun carbon nanofibers modified electrode. Talanta 83, 1410 (2011). http://dx.doi.org/10.1016/j.talanta.2010.11.019.

[80] Hood AR, Saurakhiya N, Deva D, Sharma A, Verma N. Development of bimetal-grown multi-scale carbon micro-nanofibers as an immobilizing matrix for enzymes in biosensor applications. Mater Sci Eng C, 33, 4313 (2013). http://dx.doi.org/10.1016/j. msec.2013.06.030

[81] Cui K, Song Y, Guo Q, Xu F, Zhang Y, Shi Y, Wang L, Hou H, Li Z. Architecture of electrospun carbon nanofibers-hydroxyapatite composite and its application act as a platform in biosensing. Sens Actuators B, 160, 435 (2011). http://dx.doi.org/10.1016/j. snb.2011.08.005.

[82] Hu G, Zhou Z, Guo Y, Hou H, Shao S. Electrospun rhodium nanoparticle-loaded carbon nanofibers for highly selective amperometric sensing of hydrazine. Electrochem Commun, 12, 422 (2010). http://dx.doi.org/10.1016/j.elecom.2010.01.009.

[83] Song Y, He Z, Xu F, Hou H, Wang L. pH-controlled electrocatalysis of amino acid based on electrospun cobalt nanoparticles-loaded carbon nanofibers. Sens Actuators B, 166-167, 357 (2012). http:// dx.doi.org/10.1016/j.snb.2012.02.069.

[84] Liu Y, Wang D, Xu L, Hou H, You T. A novel and simple route to prepare a Pt nanoparticle-loaded carbon nanofiber electrode for hydrogen peroxide sensing. Biosensors Bioelectron, 26, 4585 (2011). http://dx.doi.org/10.1016/j.bios.2011.05.034.

[85] Lee JS, Kwon OS, Park SJ, Park EY, You SA, Yoon H, Jang J. Fabrication of ultrafine metal-oxide-decorated carbon nanofibers for DMMP sensor application. ACS Nano, 5, 7992 (2011). http:// dx.doi.org/10.1021/nn202471f.

[86] Zhang L, Wang X, Zhao Y, Zhu Z, Fong H. Electrospun carbon nano-felt surface-attached with Pd nanoparticles for hydrogen sensing application. Mater Lett, 68, 133 (2012). http://dx.doi. org/10.1016/j.matlet.2011.10.064.

[87] Yang Y, Mei-Hua Z, Gang X, Zheng-Xiong J. Preparation and characterization of PAN-based ultra-fine activated carbon fiber adsorbent. J Porous Mater, 18, 379 (2011). http://dx.doi.org/10.1007/ s10934-010-9388-y.

[88] Ma H, Hsiao BS, Chu B. Electrospun nanofibrous membrane for heavy metal ion adsorption. Curr Org Chem, 17, 1361 (2013). http://dx.doi.org/10.2174/1385272811317130003.

[89] Bai Y, Huang ZH, Wang MX, Kang F. Adsorption of benzene and ethanol on activated carbon nanofibers prepared by electrospinning. Adsorption, 19, 1035 (2013). http://dx.doi.org/10.1007/ s10450-013-9524-5.

[90] Lee KJ, Shiratori N, Lee GH, Miyawaki J, Mochida I, Yoon SH, Jang J. Activated carbon nanofiber produced from electrospun polyacrylonitrile nanofiber as a highly efficient formaldehyde adsorbent. Carbon, 48, 4248 (2010). http://dx.doi.org/10.1016/j.carbon.2010.07.034.

[91] Schneiderman S, Zhang L, Fong H, Menkhaus TJ. Surface-functionalized electrospun carbon nanofiber mats as an innovative type 
of protein adsorption/purification medium with high capacity and high throughput. J Chromatogr, 1218, 8989 (2011). http://dx.doi. org/10.1016/j.chroma.2011.10.024.

[92] Si Y, Ren T, Li Y, Ding B, Yu J. Fabrication of magnetic polybenzoxazine-based carbon nanofibers with $\mathrm{Fe}_{3} \mathrm{O}_{4}$ inclusions with a hierarchical porous structure for water treatment. Carbon, 50, 5176 (2012). http://dx.doi.org/10.1016/j.carbon.2012.06.059.

[93] Jain S, Webster TJ, Sharma A, Basu B. Intracellular reactive oxidative stress, cell proliferation and apoptosis of Schwann cells on carbon nanofibrous substrates. Biomaterials, 34, 4891 (2013). http:// dx.doi.org/10.1016/j.biomaterials.2013.03.055.

[94] Czarnecki JS, Lafdi K, Joseph RM, Tsonis PA. Hybrid carbon-based scaffolds for applications in soft tissue reconstruction. Tissue Eng A, 18, 946 (2012). http://dx.doi.org/10.1089/ten.tea.2011.0533.

[95] Liu H, Cai Q, Lian P, Fang Z, Duan S, Ryu S, Yang X, Deng X. The biological properties of carbon nanofibers decorated with $\beta$-tricalcium phosphate nanoparticles. Carbon, 48, 2266 (2010). http://dx.doi.org/10.1016/j.carbon.2010.02.042.

[96] Yang Q, Sui G, Shi YZ, Duan S, Bao JQ, Cai Q, Yang XP. Osteocompatibility characterization of polyacrylonitrile carbon nanofibers containing bioactive glass nanoparticles. Carbon, 56, 288 (2013). http://dx.doi.org/10.1016/j.carbon.2013.01.014. 